\title{
Comparison of the Internal Energy Deposition of Direct Analysis in Real Time and Electrospray Ionization Time-of-Flight Mass Spectrometry
}

\author{
Glenn A. Harris,* Dana M. Hostetler,* Christina Y. Hampton, and \\ Facundo M. Fernández \\ School of Chemistry and Biochemistry, Georgia Institute of Technology, Atlanta, Georgia, USA
}

The internal energy $\left(\mathrm{E}_{\text {int }}\right)$ distributions of a series of $p$-substituted benzylpyridinium ions generated by both direct analysis in real time (DART) and electrospray ionization (ESI) were compared using the "survival yield" method. DART mean $\mathrm{E}_{\text {int }}$ values at gas flow rates of 2, 4, and $6 \mathrm{~L} \mathrm{~min}{ }^{-1}$, and at set temperatures of 175,250 , and $325^{\circ} \mathrm{C}$ were in the $1.92-2.21 \mathrm{eV}$ range. ESI mean $\mathrm{E}_{\text {int }}$ at identical temperatures in aqueous and $50 \%$ methanol solutions ranged between 1.71 and $1.96 \mathrm{eV}$, and 1.53 and $1.63 \mathrm{eV}$, respectively. Although the results indicated that ESI is a "softer" ionization technique than DART, there was overlap between the two techniques for the particular time-of-flight mass spectrometer used. As a whole, there was an increase in $\mathrm{E}_{\text {int }}$ with increasing reactive and drying gas temperatures for DART and ESI, respectively, indicating thermal ion activation. Three dimensional computational fluid dynamic simulations in combination with direct temperature measurements within the DART ionization region revealed complex inversely coupled fluid-thermal phenomena affecting ion $E_{\text {int }}$ values during atmospheric transport. Primarily, that DART gas temperature in the ionization region was appreciably less than the set gas temperature of DART due to the set gas flow rates. There was no evidence of $E_{\text {int }}$ deposition pathways from metastable-stimulated desorption, but fragmentation induced by high-energy helium metastables was observed at the highest gas flow rates and temperatures. (J Am Soc Mass Spectrom 2010, 21, 855-863) (C) 2010 American Society for Mass Spectrometry

$\mathrm{T}$ The development and application of ambient ionization techniques have grown at a steady pace for the last 5 years [1, 2]. Ambient ionization techniques facilitate analysis at atmospheric pressure in the open air, devoid from the constraints of typical ion source enclosures, enabling a variety of rapid screening and high-throughput applications [3]. One of the more widely used and investigated ambient MS ionization techniques is direct analysis in real time (DART) [4]. Mechanistically similar to atmospheric pressure chemical ionization (APCI) [5] and atmospheric pressure photoionization (APPI) [6], DART offers the additional ability to directly ionize analytes in the gaseous, liquid, or solid states. DART uses a point-to-plane atmospheric pressure glow discharge to generate metastable species in a chamber that is physically separated from the ionization region. These metastables are heated and directed through a grid electrode that prevents ion-ion and ion-electron recombination of ionic species generated within the DART ionization source. The most prevalent mechanism proposed for the formation of

Address reprint requests to Professor F. M. Fernández, School of Chemistry and Biochemistry, Georgia Institute of Technology, 770 State St., Atlanta, Georgia 30317, USA. E-mail: facundo.fernandez@chemistry.gatech.edu

* These authors contributed equally to this work. positive ions by DART involves Penning ionization of atmospheric water molecules induced by collisions with electronically-excited metastable helium atoms $\left(\mathrm{He}^{*}{ }^{3} \mathrm{~S}_{1}, 19.8 \mathrm{eV}\right)(\mathrm{eq} 1)[4]$ :

$$
\mathrm{He}^{*}(g)+n \mathrm{H}_{2} \mathrm{O}(\mathrm{g}) \rightarrow \mathrm{He}(\mathrm{g})+\left(\mathrm{H}_{2} \mathrm{O}\right)_{n-1} \mathrm{H}^{+}(g)+\mathrm{OH}^{-}(g)
$$

Protonated water clusters of different sizes react with thermally-desorbed molecules (AB) (eq 2a) to undergo proton transfer to different extents depending on $n$ (eq 2b) [7].

$$
\begin{aligned}
& A B(s) \stackrel{\text { heat }}{\longrightarrow} A B(g) \\
& A B(g) \stackrel{\left(\mathrm{H}_{2} \mathrm{O}\right)_{n-1} \mathrm{H}^{+}(g)}{\longrightarrow} A B\left(\mathrm{H}_{2} \mathrm{O}\right)_{n-2} H^{+}(g) \\
& \quad+\mathrm{H}_{2} \mathrm{O}(\mathrm{g}) \stackrel{-(n-2) \mathrm{H}_{2} \mathrm{O}}{\longrightarrow} A B H^{+}(g)
\end{aligned}
$$

Another ionization mechanism that has been observed under high grid voltages, small DART to mass inlet spacing, and low humidity conditions is direct Penning ionization of desorbed analytes [8]. This mechanism produces electron ionization-like spectra (eq 3) for low polarity compounds with low proton affinities. Under 
these conditions, charge exchange reactions with diatomic oxygen molecular ions can also occur (eq $4 \mathrm{a}$ and b) [8].

$$
\begin{aligned}
& \mathrm{He}^{*}(g)+\mathrm{AB}(g) \rightarrow \mathrm{He}(g)+A B^{+} \cdot(g)+e^{-} \\
& \mathrm{He}^{*}(g)+\mathrm{O}_{2}(g) \rightarrow \mathrm{He}(g)+\mathrm{O}_{2}^{+}(g)+e^{-} \\
& \mathrm{O}_{2}^{+}(g)+A B(g) \rightarrow \mathrm{O}_{2}(g)+A B^{+} \cdot(g)
\end{aligned}
$$

In addition to the intrinsic prevalence of these various ionization pathways, the complexity of the coupled fluid and thermal dynamic, electrical field, and sample positioning effects present in DART ionization can lead to differences in ion transmission and activation efficiencies. To completely develop DART as a mature analytical tool for direct MS analysis, further research into the physicochemical processes governing ionization, ion transport, and activation is needed $[7,9]$.

To date, the majority of internal energy $\left(\mathrm{E}_{\text {int }}\right)$ deposition studies have focused primarily on spray- [10-12] and laser- $[13,14]$ based desorption/ionization techniques. $E_{\text {int }}$ deposition studies of ions generated by APCI have focused on post-source $E_{\text {int }}$ contributions to fragmentation [15] or isomerization [16] during insource and tandem MS collision induced dissociation (CID). Previously, the $\mathrm{E}_{\text {int }}$ deposition of desorption electrospray ionization (DESI) has been investigated, yielding insight on ion formation and energetics of this ambient ionization technique [12]. To our knowledge, this is the first investigation into the $\mathrm{E}_{\mathrm{int}}$ deposited during DART ionization, not only providing an extensive comparison with standard electrospray ionization (ESI), but also furthering insights into the physicochemical phenomena involved in DART.

\section{Experimental}

\section{Synthesis and Preparation of Para-Substituted Benzylpyridinium Salts}

The $p$-substituted methyl- $\left(\mathrm{CH}_{3}\right)$, chloro- $(\mathrm{Cl})$, cyano$(\mathrm{CN})$, and nitro $\left(\mathrm{NO}_{2}\right)$ benzylpyridinium compounds were synthesized by condensation of the $p$-substituted benzyl halide with pyridine followed by recrystallization from diethyl ether as described by Katritzky et al. [17]. Pyridine, nitromethane, anhydrous diethyl ether, anhydrous ethanol, and the benzyl halide starting reagents were all used without further purification (Sigma-Aldrich, St. Louis, MO, USA). The methoxy$\left(\mathrm{OCH}_{3}\right)$ substituted compound was purchased (Arkat USA, Inc., Gainesville, FL, USA). All samples were stored in a $-80{ }^{\circ} \mathrm{C}$ freezer when not in use to minimize degradation. For DART experiments, an equimolar thermometer ion mixture $(100 \mu \mathrm{M})$ was prepared in nanopure water (Barnstead International, Dubuque, IA, USA), while for ESI experiments, a $1 \mu \mathrm{M}$ mixture was prepared in either a nanopure water or $50 \%$ methanol (Sigma-Aldrich) solution.

\section{DART-TOF MS Sampling, Instrumentation, and Data Acquisition}

DART samples were prepared by pipetting $5 \mu \mathrm{L}$ aliquots of the sample mixture onto the tips of DIP-it sample capillaries (IonSense, Inc., Saugus, MA, USA) and allowing the drops to dry for $30 \mathrm{~min}$. Sample deposition was repeated eight times so that a total of 4 nmol of each compound was deposited on the capillary. Capillaries were affixed to an in-house built sample holder attached to a hinged right-angle sample arm (Thorlabs, Newton, NJ, USA) for reproducible sample placement during all experiments.

MS analysis was performed with a commercial DART ionization source (IonSense, Inc.) and a JMS100TLC (AccuTOF) orthogonal acceleration time-offlight (TOF) mass spectrometer (JEOL USA, Peabody, MA, USA). All experiments were performed in positive ion mode. Ion optics settings were as follows: inlet (orifice 1) temperature: $80^{\circ} \mathrm{C}$, orifice 1 voltage: $20 \mathrm{~V}$, ring electrode voltage: $10 \mathrm{~V}$, orifice 2 voltage: $5 \mathrm{~V}$, ion guide bias voltage: $27 \mathrm{~V}$, ion guide peaks voltage: $300 \mathrm{~V}$. The detector voltage was set to $2750 \mathrm{~V}$. A lower orifice 1 voltage was required for DART than for ESI, since it improved sensitivity [7]. Preliminary experiments with DART at higher orifice 1 voltages $(40$ and $60 \mathrm{~V})$ resulted in overall low sensitivity, with the higher critical energy $\left(E_{o}\right)$ ions remaining undetected, thus withholding the ability to conduct reliable $\mathrm{E}_{\text {int }}$ statistical calculations.

DART ion source settings were as follows: discharge needle voltage: $3600 \mathrm{~V}$, discharge electrode voltage: 150 $\mathrm{V}$, grid electrode voltage: $100 \mathrm{~V}$, distance between ion source and spectrometer inlet: $1.5 \mathrm{~cm}$, distance of sample capillary to MS orifice: $0.60 \mathrm{~cm}$, capillary depth below MS orifice: $0.16 \mathrm{~cm}$, and capillary distance to the center of the DART gas nozzle: $0.74 \mathrm{~cm}$ (Figure 1). The

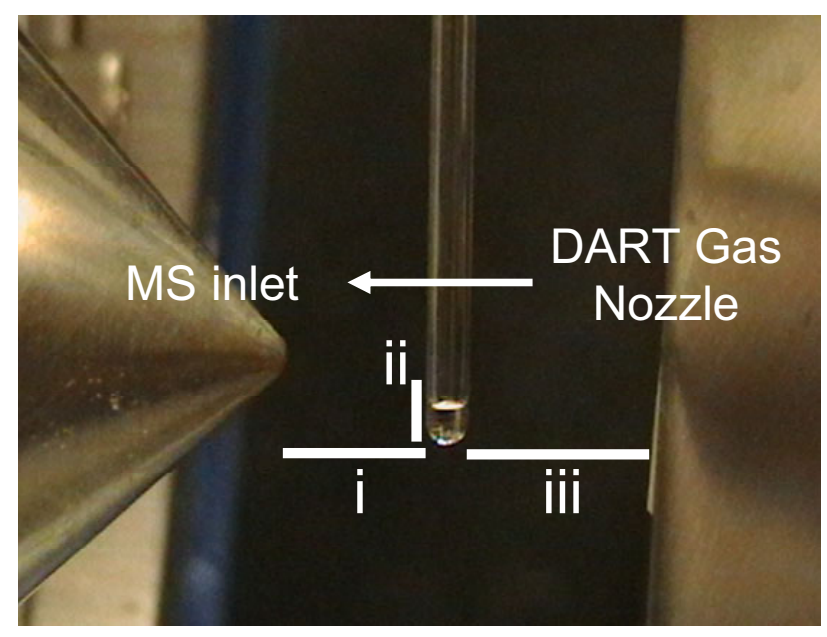

Figure 1. Sample placement for DART-TOF MS analysis of thermometer compounds. Samples were applied to DIP-it (diameter $0.16 \mathrm{~cm}$ ) sample capillaries affixed to a stable sampling arm. Sample positioning distances: (i) center of MS orifice to capillary, $0.60 \mathrm{~cm}$, (ii) capillary depth below center of MS orifice, $0.16 \mathrm{~cm}$, and (iii) capillary to center of gas outlet distance, $0.74 \mathrm{~cm}$. 
rate of helium gas flow through the DART was 2, 4, or $6 \mathrm{~L} \mathrm{~min}^{-1}$, and the set heater temperature was 175,250 , or $325^{\circ} \mathrm{C}$. A solution of polyethylene glycol 600 (PEG, Sigma Aldrich, St. Louis, MO, USA) prepared in 50\% methanol was used as the mass calibration standard. A sample capillary dipped in the PEG solution was placed in front of the helium stream for $60 \mathrm{~s}$, and a reference mass spectrum was obtained. Ultra high purity helium (99.999\%; Airgas, Atlanta, GA, USA) was used in all DART experiments. Sample capillaries were held in the ionization region for $60 \mathrm{~s}$. Mass spectral data processing, calibration, and background subtraction were performed using the built-in mass spectrometer software (MassCenter, ver. 1.3). The temperature at the tip of the DIP-it capillary was determined with an $80 \mathrm{BK}$ temperature probe connected to a digital multimeter (Fluke 179-True RMS; Everett, WA, USA). Ultra high purity nitrogen (99.995\%; Airgas) was used following the exact procedure as helium experiments, but only the low dissociation energy compounds $\left(p-\mathrm{OCH}_{3}, p-\mathrm{CH}_{3}\right.$, and $p-\mathrm{Cl}$ ) were detected in this case. This result made $\mathrm{E}_{\text {int }}$ calculations impossible due to the lack of data points on the fitted survival yield curves (see below). The lower vibrionic metastable energy level of nitrogen, and its lower thermal conductivity are believed to be the primary responsible factor for the low sensitivity [4].

\section{ESI-TOF MS Experiments, Instrumentation, and Data Acquisition}

For ESI-TOF MS experiments, the DART ion source mounted onto the TOF mass spectrometer was replaced by the a pneumatically-assisted micro-ESI source (JEOL USA). In this source, the nebulizing gas flows orthogonally (pointing downwards) to the MS inlet orifice, while the drying (desolvating) gas is applied coaxially to the ESI needle assembly passing through a heated metal block (Supplementary Information, which can be found in the electronic version of this article, Figure S-1) to enhance desolvation. All mass spectrometer settings were identical to those used for DART-TOF MS experiments, with the exception that the orifice 1 voltage was set to $50 \mathrm{~V}$ for ESI, the minimum setting that produced sufficient sensitivity. A $1 \mu \mathrm{M}$ solution containing all five $p$-substituted benzylpyridinium compounds prepared in either nanopure water or $50 \%$ methanol was delivered to the ion source with a liquid handling pump (VICI M6; Valco Instruments Co., Houston, TX, USA). For the $50 \%$ methanol solution, the flow rate used was $200 \mu \mathrm{L} \min ^{-1}$. Due to the difficulty of desolvating aqueous droplets, however, a lower flow rate $(150 \mu \mathrm{L}$ $\mathrm{min}^{-1}$ ) was required to produce a stable spray from the aqueous solution. A 1:10 000 dilution of the PEG solution was used as the mass calibration standard. Ion source settings were as follows: desolvation and nebulizing gas: nitrogen (99.995\%; Airgas), desolvation gas flow rate: $1 \mathrm{~L} \mathrm{~min}^{-1}$, nebulizing gas flow rate: $2.5 \mathrm{~L}$ $\min ^{-1}$, desolvating chamber temperature: 175,250 , or $325^{\circ} \mathrm{C}$, and needle voltage: $2500 \mathrm{~V}$. Mass spectral data acquisition, processing, and calibration settings were identical to those used in DART-TOF MS experiments.

\section{Survival Yield Method and Data Analysis}

Uncontrolled ion activation within the ion source leads to an increase in the ions' $\mathrm{E}_{\text {int }}$ [18]. Defined by Vékey as the "amount of energy an ion contains above the ground electronic, vibrational, and rotational states" [19], $E_{\text {int }}$ is a significant factor in determining ion fragmentation yields [10]. Because of the heterogeneity of the processes occurring in atmospheric pressure and ambient ionization, the extent of ion activation is better described by $\mathrm{P}(\mathrm{E})$, the normalized probability distribution that an ion has a given $E_{\text {int }}[10,19]$. Many methods have been developed to determine $\mathrm{P}(\mathrm{E})$ including the "thermometer molecule" method [20], the "deconvolution method" [21], and the method used in this study, the "survival yield" (SY) method [22, 23]. The SY method assumes that: (1) all ions with $\mathrm{E}_{\mathrm{int}}$ below a critical energy, $\mathrm{E}_{\mathrm{O}}$, do not dissociate and appear as intact ionic species, and (2) all ions with $E_{\text {int }}$ above $E_{o}$ will dissociate into fragment ions [10, 12]. Experiments are performed with a series of $p$-substituted benzylpyridinium salts with well characterized thermodynamic properties and a similar number of degrees of freedom. The prevailing fragmentation pathway commonly observed for these salts is dissociation forming pyridine and a $p$-substituted benzyl cation at a known $\mathrm{E}_{\mathrm{o}}$ (Scheme 1). Following ionization, the ratio of the precursor $\left(\mathrm{I}_{\text {prec }}\right)$ and fragment $\left(\mathrm{I}_{\text {frag }}\right)$ ion intensities is calculated (eq 5) [22, 23].

$$
S Y_{\text {Exp }}=\frac{I_{\text {prec }}}{I_{\text {prec }}+I_{\text {frag }}}
$$

SY values are then plotted against their respective $E_{o}$ and two points corresponding to a SY value of 0 at $0 \mathrm{eV}$ (indicating that no precursor ions would survive if the associated critical energy was $0 \mathrm{eV}$ ) and a SY value of 1 at $3.5 \mathrm{eV}$ (indicating that at high critical energies, no fragment ions would be observed) are added before fitting the curve to a sigmoidal function (eq 6).

$$
\mathrm{SY}_{\mathrm{Fitted}}=\frac{\mathrm{a}}{1+\exp ^{-}\left(\frac{\text { Energy }-\mathrm{x}_{0}}{\mathrm{~b}}\right)}=\int_{\gamma}^{\infty} P(E) d E
$$

The $S Y_{\text {Fitted }}$ curve parameters, $a, b$, and $x_{0}$, are experimentally fitted variables. The $\mathrm{E}_{\mathrm{int}}$ distribution is deter-

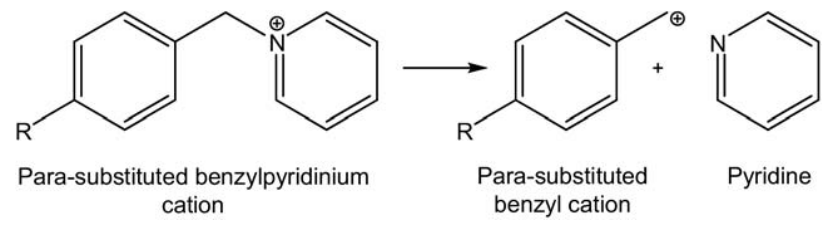

Scheme 1. $p$-Substituted benzylpyridinium cation structure and typical fragmentation pathway. 
mined by taking the first derivative of the sigmoid curve, generating the $\mathrm{P}(\mathrm{E})$ curve. The mean $\mathrm{E}_{\text {int }},\left\langle\mathrm{E}_{\mathrm{O}}>\right.$, is then calculated by determining the centroid of $P(E)$ (eq 7).

$$
<\mathrm{E}_{\mathrm{o}}>=\frac{\int_{0}^{\infty} E \cdot P(E) d E}{\int_{0}^{\infty} P(E) d E}
$$

For data analysis, spectra were averaged for one minute using the built-in mass spectrometer software (MassCenter, ver. 1.3) and exported into Excel (Microsoft, Auburn, WA, USA). After manually selecting peak maxima for the ions of interest, and calculating survival yields of each (eq 5), the data were treated with an in-house programmed macro in SigmaPlot (Systat Software Inc., San Jose, CA, USA) to fit the survival yields to a sigmoid curve and to calculate the residual error of the fit, $\mathrm{E}_{\mathrm{int}}$ distribution, mean $\mathrm{E}_{\mathrm{int}}$, and the full width half-maximum of the distribution.

\section{Computational Fluid Dynamics Simulations}

A three-dimensional design geometry file was created depicting the accurate dimensions of the DART gas exit nozzle, sample capillary, and MS inlet orifice with the computer-aided design program within the COMSOL Multiphysics (COMSOL, Inc., Burlington, MA, USA) finite element analysis environment. The modeled flow rate settings matched those used in the DART experiments. All models were built in the absence of electric fields and without regard to the influence of reduced pressure transport originating at the inlet of the mass spectrometer. The relative spacing between the ion source gas outlet, sample capillary, and MS orifice used during DART analysis were incorporated into the model. Particle tracing plots were generated from 40 particles randomly placed on the external perimeter of the bottom capillary tip by the finite element modeling software. Time-resolved simulations of the first $100 \mathrm{~ms}$ of sampling were performed on a dual Intel Xeon quad core $(2.66 \mathrm{GHz})$ computer with $8 \mathrm{~GB}$ memory and 1.5 GB video memory. Simulations required between 0.5 and $18 \mathrm{~h}$ to complete depending on the chosen conditions, with higher flow rates requiring longer due to the increased complexity of the fluid dynamics. Due to the mechanical complexity of the ESI source, it was not possible to accommodate the computational demand necessary to generate equivalent simulations.

\section{Results and Discussion}

\section{Determination of the $E_{\text {int }}$ Deposition of DART Compared to ESI}

Various energy-depositing processes occur during DART ionization. For the thermometer compounds tested here, potential energy deposition pathways begin with the thermal desorption of the solid neutral salt into the gaseous phase (Scheme 2i). The neutral salt undergoes charge splitting to form the halide anion and the precursor cation via atmospheric pressure thermal desorption ionization (APTDI), [24] and/or the effect of the electric field established between the needle electrode, grid electrode, and the mass spectrometer inlet orifice (Scheme 2ii). Further activation of the precursor cation proceeds through additional heating (Scheme 2iii), reactive collisions with metastable He species

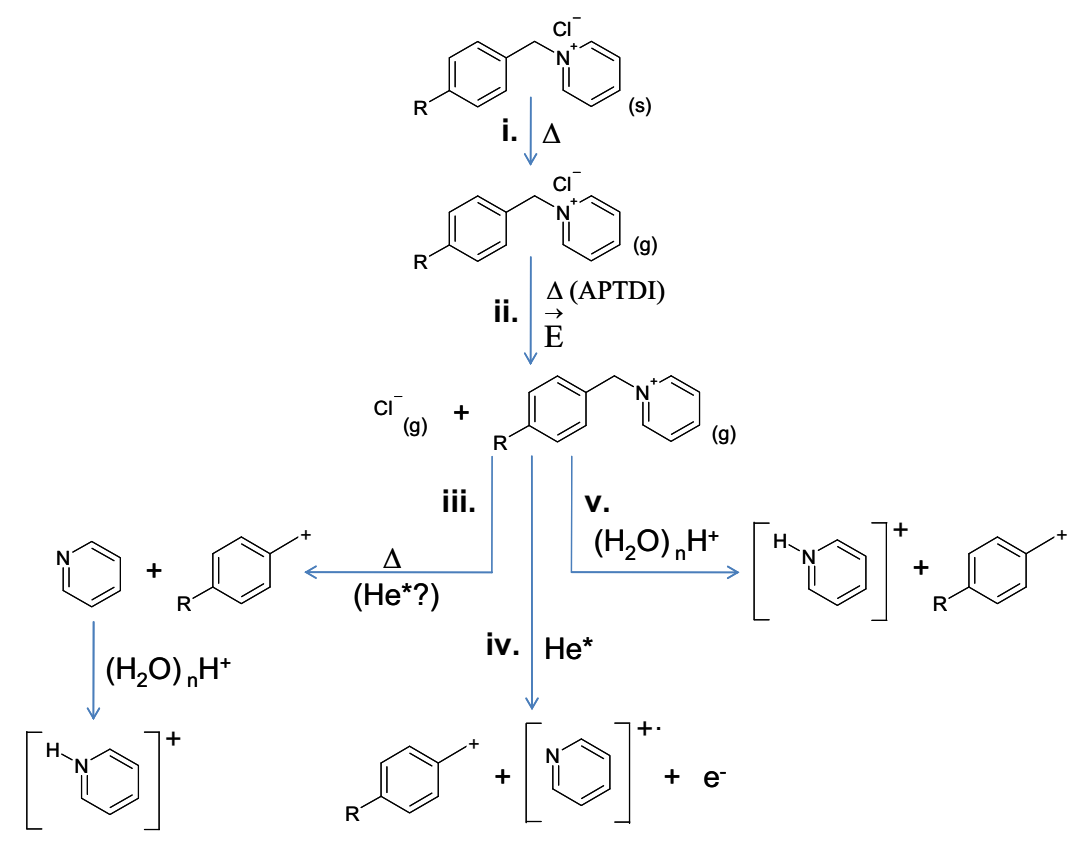

Scheme 2. Proposed energy deposition pathways for the compounds analyzed by DART-TOF MS. 
$\left(\mathrm{He}^{*}\right)$ (Scheme 2iv), and/or deposition of excess energy released during proton transfer from protonated water clusters (Scheme 2v).

At the lowest assayed helium gas heater (DART) or desolvating chamber (ESI) temperature set point $\left(175^{\circ} \mathrm{C}\right)$, both aqueous and $50 \%$ methanol solutions probed by ESI had lower $<\mathrm{E}_{\mathrm{o}}>$ values (1.71 eV and 1.53 $\mathrm{eV}$, respectively) compared with DART at all three gas flow rates tested $\left(2 \mathrm{~L} \mathrm{~min}^{-1}: 1.92 \mathrm{eV}, 4 \mathrm{~L} \mathrm{~min}^{-1}: 2.02 \mathrm{eV}\right.$, and $6 \mathrm{~L} \mathrm{~min}^{-1}: 2.08 \mathrm{eV}$ ) (Figure 2a). In comparison to the softest ESI conditions with a $50 \%$ methanol solution, at $175{ }^{\circ} \mathrm{C}, \mathrm{DART}\left\langle\mathrm{E}_{\mathrm{o}}>\right.$ values were higher by $25 \%$, $32 \%$, and $36 \%$ at 2,4 , and $6 \mathrm{~L} \mathrm{~min}^{-1}$, respectively. The same trend followed at $250^{\circ} \mathrm{C}$ (Figure $2 \mathrm{~b}$ ), correspond-
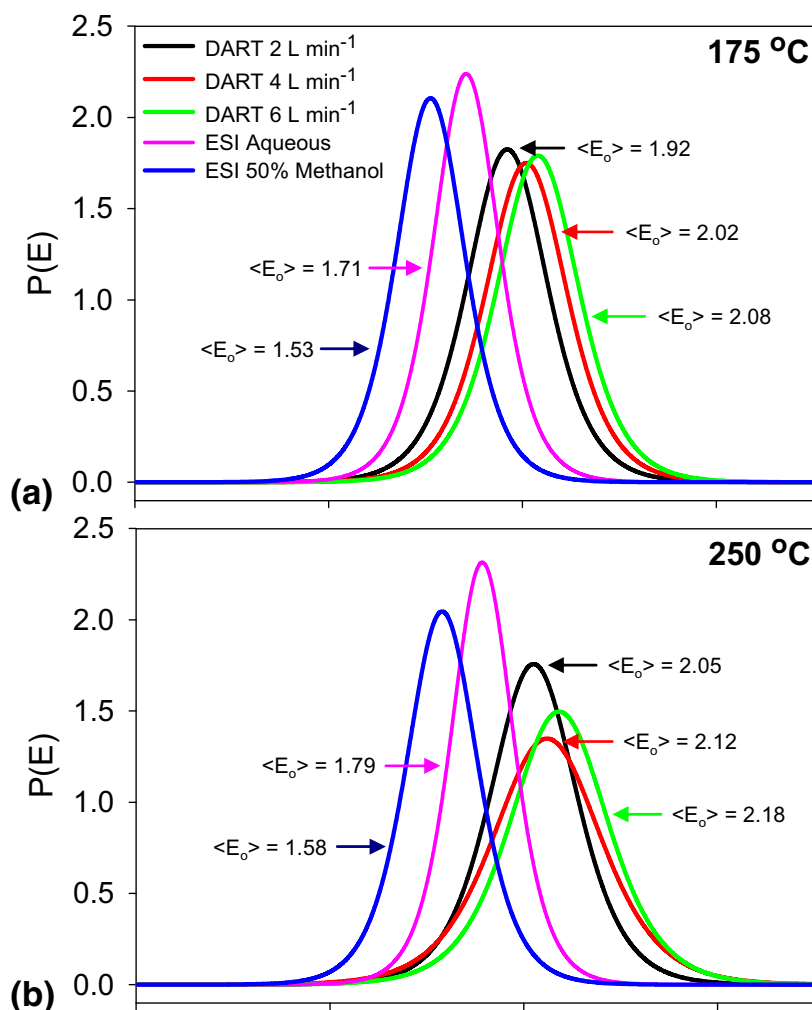

(b)

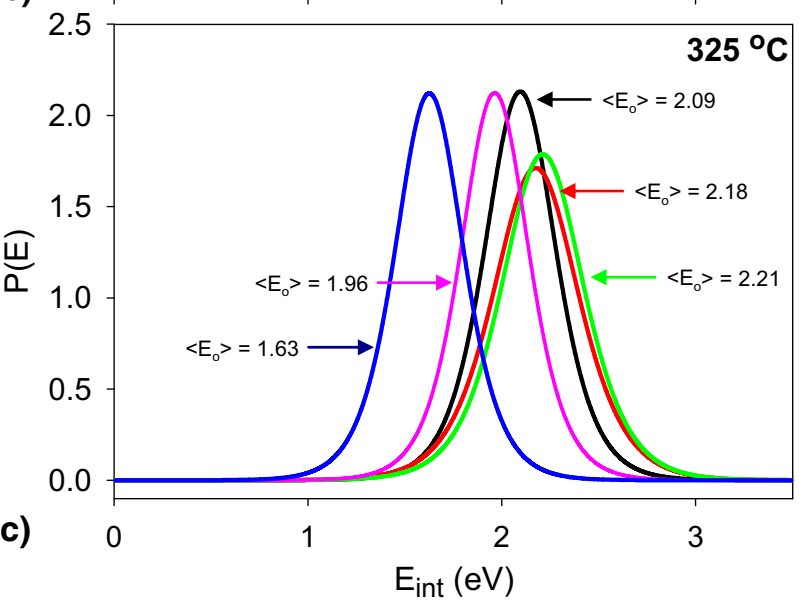

Figure 2. Mean $\left.\mathrm{E}_{\text {int }}\left(<\mathrm{E}_{\mathrm{o}}\right\rangle\right)$ distributions for DART and ESI with helium gas heater (DART) or desolvation chamber (ESI) temperature set points of (a) $175^{\circ} \mathrm{C}$, (b) $250^{\circ} \mathrm{C}$, and (c) $325^{\circ} \mathrm{C}$. ing to DART $<\mathrm{E}_{\mathrm{o}}>$ values that were higher than $50 \%$ methanol ESI values by $30 \%, 34 \%$, and $38 \%$ at 2,4 , and $6 \mathrm{~L} \mathrm{~min}^{-1}$, respectively. Furthermore, $\left\langle\mathrm{E}_{\mathrm{o}}>\right.$ values at $325^{\circ} \mathrm{C}$ for DART (2 $\mathrm{L} \mathrm{min}^{-1}: 2.09 \mathrm{eV}, 4 \mathrm{~L} \mathrm{~min}^{-1}: 2.18 \mathrm{eV}$, and $6 \mathrm{~L} \mathrm{~min}^{-1}: 2.21 \mathrm{eV}$ ) were higher than the comparable experiments for the $50 \%$ methanol ESI values by $28 \%, 33 \%$, and $35 \%$ at 2,4 , and $6 \mathrm{~L} \mathrm{~min}^{-1}$, respectively (Figure 2c). The shape of the $\mathrm{E}_{\text {int }}$ distributions displayed no asymmetric tailing at all temperatures tested [25]. These $\left\langle\mathrm{E}_{\mathrm{O}}\right\rangle$ values indicated that under the tested conditions, ESI is a "softer" ionization technique compared to DART.

The aqueous solution analyzed by ESI had higher $\left\langle\mathrm{E}_{\mathrm{o}}\right\rangle$ values in comparison to the $50 \%$ methanol solutions by $12 \%, 13 \%$, and $20 \%$ at 175,250 , and $325^{\circ} \mathrm{C}$, respectively. Due to the higher vapor pressure of methanol, droplets produced from a 50\% methanol solution desolvate faster than aqueous droplets and cool more rapidly. The differences in $\mathrm{E}_{\text {int }}$ deposition observed between ESI experiments were consistent with prior investigations showing that $\mathrm{P}(\mathrm{E})$ could be altered by varying the solvent system vapor pressure, greatly affecting thermal and kinetic energy contributions [22]. Sprayed droplets acquire thermal energy by in-source heat conversion and friction with gas molecules to an extent that depends on droplet sizes [12, 22, 26, 27]. Kinetic energy from electric field-driven acceleration of charged droplets and ions can also be deposited into $\mathrm{E}_{\text {int }}$ modes, both in the atmospheric pressure region and within the various reduced pressure regions of the mass spectrometer interface $[10,12,28]$.

\section{Thermal Activation Pathways}

In ESI, heated gas serves the role of improving charged droplet desolvation before entering the ion transfer optics region $[29,30]$. This differs from the role of the heated gas used in DART experiments, which is to evaporate residual solvent and thermally desorb the analytes. If set high enough, high DART and ESI gas temperatures induce unwanted fragmentation of labile species. It is quite important to distinguish between the DART temperature set by software, and the actual temperature within the ionization region. Measured gas temperatures at the bottom of the sample capillaries rapidly decreased upon increasing the flow rate setting as a result of rapid convective cooling of the ionization source environment. Direct temperature measurements (Figure 3) indicated that the actual gas temperature was consistently lower than the set value, and that the difference between the two increased with increasing flow rates. When the heater was set at $175^{\circ} \mathrm{C}$ (Figure $3 \mathrm{a})$, the average steady-state gas temperatures at 2, 4, and $6 \mathrm{~L} \mathrm{~min}{ }^{-1}$ were $163{ }^{\circ} \mathrm{C}, 145^{\circ} \mathrm{C}$, and $136^{\circ} \mathrm{C}$, respectively. This downward trend was the same for set temperatures of $250{ }^{\circ} \mathrm{C}\left(2 \mathrm{~L} \mathrm{~min}^{-1}: 227^{\circ} \mathrm{C}, 4 \mathrm{~L} \mathrm{~min}^{-1}\right.$ : $200^{\circ} \mathrm{C}$, and $6 \mathrm{~L} \mathrm{~min}^{-1}: 187^{\circ} \mathrm{C}$ ) (Figure $\left.3 \mathrm{~b}\right)$ and $325^{\circ} \mathrm{C}(2$ 

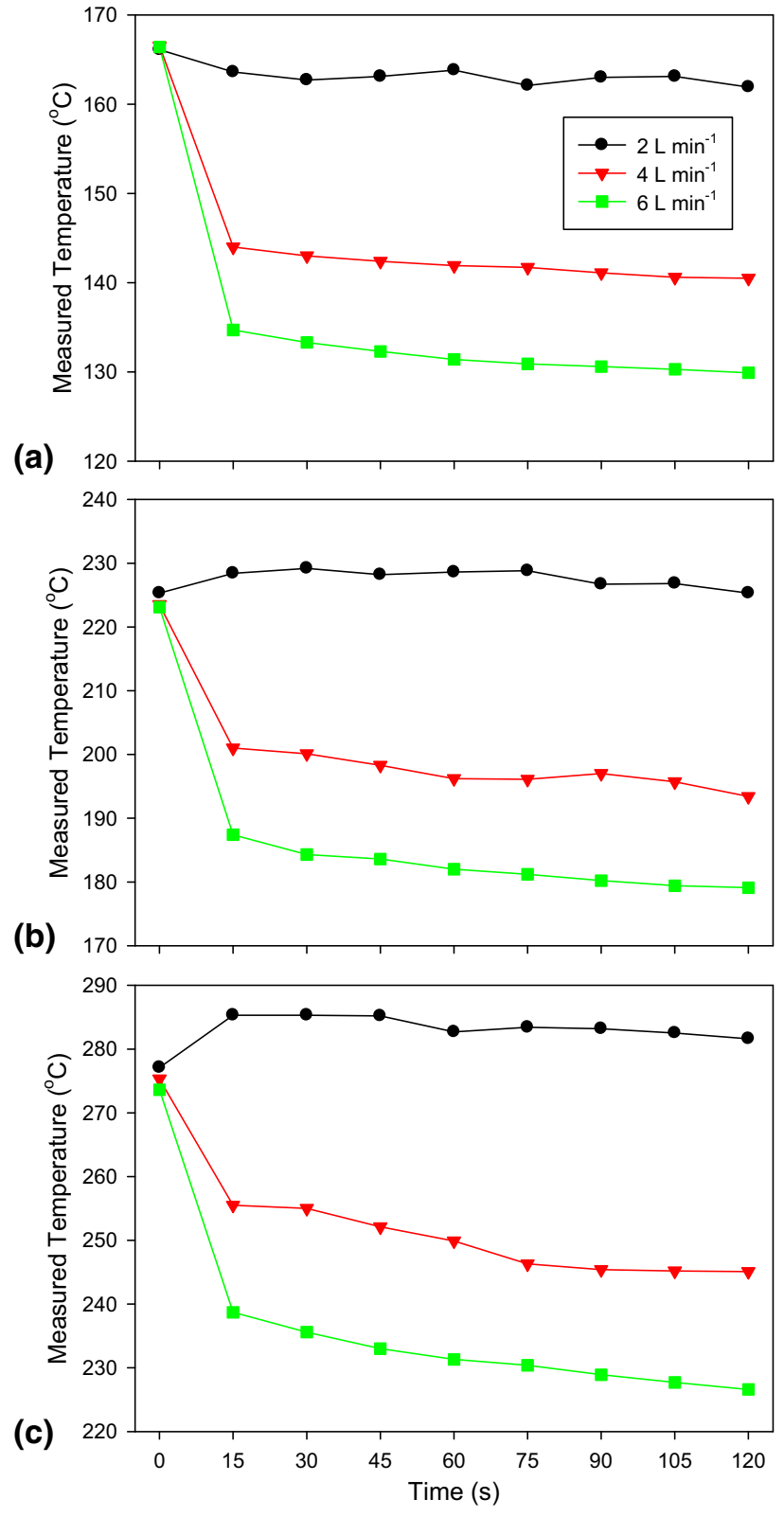

Figure 3. Measured gas temperature at the bottom of the sample capillary in the DART ionization region at experimental set temperatures of (a) $175^{\circ} \mathrm{C},\left(\right.$ b) $250^{\circ} \mathrm{C}$, and (c) $325^{\circ} \mathrm{C}$. Time $\mathrm{t}=0 \mathrm{~s}$ corresponds to the instant the gas flow is turned on in the preheated DART source.

$\mathrm{L} \min ^{-1}: 283^{\circ} \mathrm{C}, 4 \mathrm{~L}^{-1} \min ^{-1}: 252^{\circ} \mathrm{C}$, and $6 \mathrm{~L} \mathrm{~min}^{-1}$ : $236{ }^{\circ} \mathrm{C}$ ) (Figure $3 \mathrm{c}$ ).

The measured "effective" temperatures strongly influenced the extent of $\mathrm{E}_{\text {int }}$ deposition. Ions generated at a high flow rate $\left(4\right.$ and $\left.6 \mathrm{~L} \mathrm{~min}^{-1}\right)$ at any set gas temperature were created in a thermally cooler environment compared to those created at low flow rates $(2 \mathrm{~L}$ $\min ^{-1}$ ). Ion formation in a locally cooler environment is expected to lead to a decrease in thermal-induced fragmentation $[9,25,31]$. Contour maps for the data in Figure 2 were created to assist in understanding the $E_{\text {int }}$ deposition trends observed experimentally (Supple- mentary Figure S-2). The $\mathrm{E}_{\text {int }}$ contour map for ESI indicates a decrease in $\mathrm{E}_{\text {int }}$ deposition with increasing concentrations of methanol at lower temperatures (Supplementary Figure S-2b) as previously reported in similar work [22] and discussed above. The DART map shows that the least amount of energy was deposited at lower gas flow rates and temperatures (blue on the color scale), whereas the highest energy deposition occurred at high flow rates and set temperatures (orange and red color scale, Supplementary Figure S-2a). Because lower measured gas temperatures were found at higher flow rates, thermal ion activation could not account for the increase in $\mathrm{E}_{\mathrm{int}}$ observed under those conditions.

Increase in $\left\langle\mathrm{E}_{\mathrm{o}}\right\rangle$ may also result from the excess energy released during dissociative proton transfer reactions with protonated water clusters (Scheme 2v) [32]. An increase in the intensities of protonated water cluster ions when increasing the set gas temperature was observed at all flow rates (Figure 4). At $175^{\circ} \mathrm{C}$ (Figure 4a), $250{ }^{\circ} \mathrm{C}$ (Figure $4 \mathrm{~b}$ ), and $325^{\circ} \mathrm{C}$ (Figure 4c), clusters with $n \leq 6$ were the most abundant. This suggests that the pathways shown in Scheme 2iii and $2 \mathbf{v}$ may act concurrently. The abundance of clusters with $n \geq 8$ was observed to increase at low flow rates. This is to be expected, due to the increased hydrate thermodynamic stability at higher temperatures [33]. The trend was less clear for smaller hydrates. As a whole, however, the increase observed in protonated water cluster intensities as flow rate was decreased did not explain the changes in internal energy deposition. This suggests that additional collisional activation during transit through the ion optics or other pathways, such as that shown in Scheme 2iv, may play a significant role in further determining $\left\langle\mathrm{E}_{\mathrm{o}}\right\rangle$. This alternative activation pathway involves direct Penning ionization of thermometer ions with $\mathrm{He}^{*}$ producing pyridine molecular ions $\left(\mathrm{Py}^{+}\right)$. This ionization pathway is not expected to be prevalent at low exit grid voltages and high ambient humidities (45\%) [9]. When DART mass spectra were examined in detail $\mathrm{Py}^{+}$. was detected in low abundance (Supplementary Figure S-3). As expected, protonation of the pyridine molecule was favored significantly over the formation of $\mathrm{Py}^{+}$. at all tested flow rates and temperatures with a net increase in $\mathrm{Py}^{+} \cdot$ abundance at higher effective temperatures. The relatively low abundance of $\mathrm{Py}^{+\cdot}(0.61 \%$ on average) suggests that under the present conditions, the pathway depicted in Scheme 2iv should not be considered a major contributor to changes in $\left\langle\mathrm{E}_{\mathrm{o}}\right\rangle$.

\section{Collisional Activation Effects}

In-source collision-induced dissociation (CID) is generally performed by increasing the acceleration voltages applied to orifices and skimmers in the first stage of a differentially-pumped mass spectrometric system. Higher potential differences in the first differentially pumped regions produce more energetic collisions with 


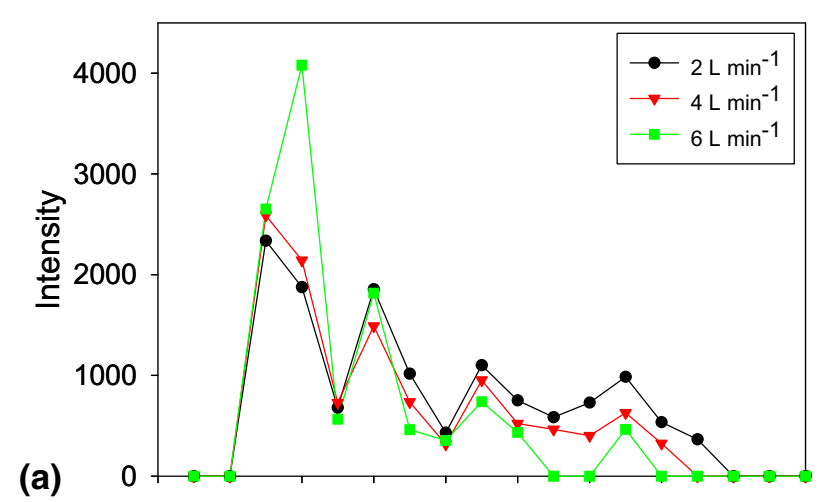

(a)
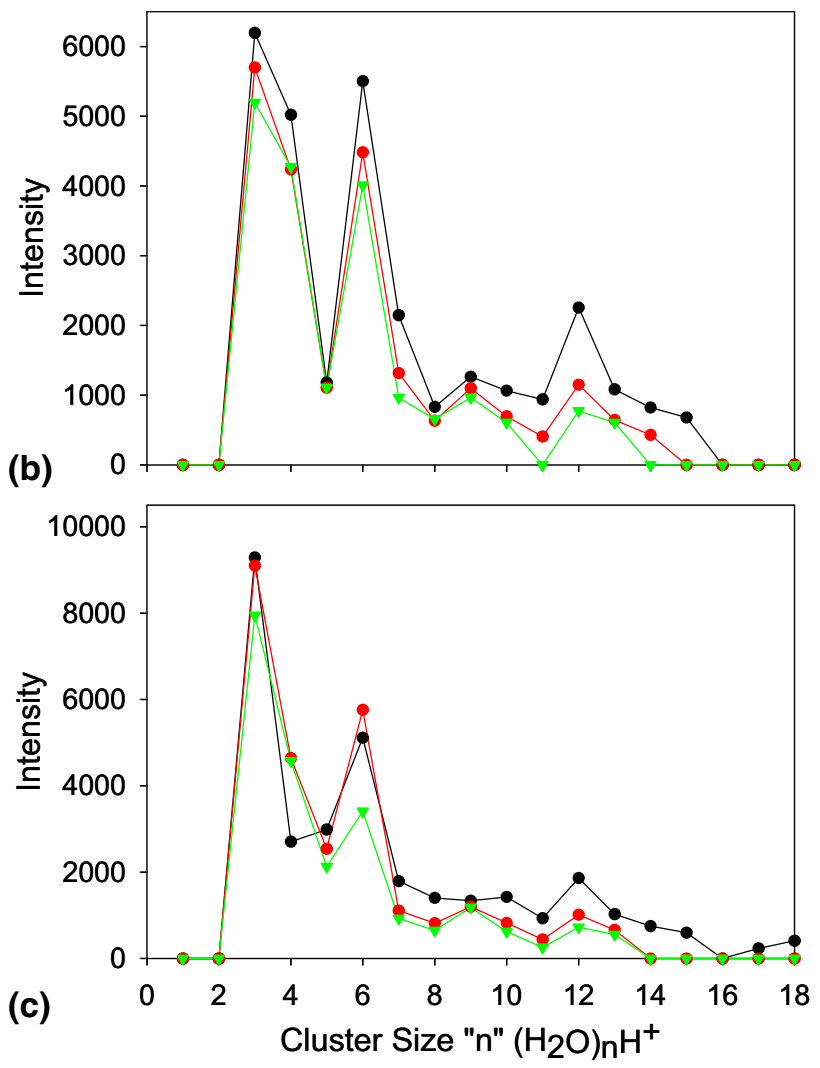

Figure 4. Observed absolute abundances of protonated water clusters with " $n$ " water molecules $\left(\left(\mathrm{H}_{2} \mathrm{O}\right)_{n} \mathrm{H}^{+}\right)$at set DART temperatures of (a) $175^{\circ} \mathrm{C}$, (b) $250^{\circ} \mathrm{C}$, and (c) $325^{\circ} \mathrm{C}$ and different glow discharge gas flow rates. The electrical current on the discharge needle monitored from the DART controller software remained constant throughout these experiments.

gaseous molecules, inducing higher fragmentation yields during ion transport towards the mass analyzer. In-source CID yields can also be influenced by the gas pressure in the spectrometer's interface [33]. As pressure $(\mathrm{P})$ in this region increases, the mean free path $(\lambda)$ decreases $(\lambda \alpha 1 / P)$ leading to a decrease in the collisional energy-transfer [34]. Ultimately, this manifests into a reduction in ion fragmentation and a decrease in the $E_{\text {int }}$ deposition [25]. To investigate the existence of this type of effect, the pressure of the first differentiallypumped region was monitored via a Pirani gauge for all DART and ESI experiments (Supplementary Table S-1).
A decrease in pressure was observed when both the DART ion source temperature and flow rate settings were increased. No changes were observed for ESI. It is thus highly likely that the increase in pressure in the first differentially pumped region as the DART gas flow rates were decreased is responsible for the lower $E_{\text {int }}$ deposition observed a given set DART gas temperature.

\section{Influence of Fluid Dynamics on $E_{\text {int }}$ Deposition}

Previous ESI energy deposition studies have shown a correlation between the ion source design, and the mean value and width of the $E_{\text {int }}$ distribution [22]. Using the DART ion source, design, and experimental variables such as sample positioning, gas temperature, and gas flow rates determine neutral and charged particle trajectories within the ionization region. Previous studies from our group have suggested that particle circulation may occur in some sampling geometries, decreasing experimental sensitivity [7]. In the present context, particle circulation may also lead to longer residence times in elevated temperature regions and/or cause more collisions with energetic metastables, reactive ions, and neutral molecules.

Particle tracing plots (Figures 5), and threedimensional time-resolved computational fluid dynamic simulations (see video links in Supplementary Table $\mathrm{S}-2)$ were generated to model the gas behavior in a commercial DART ion source. Examination of the fluid dynamic simulations showed that regardless of the gas flow rate selected, the helium stream exiting the DART source remains in a tight jet until it contacts the sample capillary in the ionization region. At that point, the gas jet splits and aerodynamically flows around the capillary despite its small o.d. $(0.16 \mathrm{~cm})$. Simulated particle trajectories derived from these simulations (Figure 5) showed that particles originating from the bottom surface of the sample capillary did not follow recirculating trajectories and, thus, $\mathrm{E}_{\text {int }}$ differences over various DART conditions are likely unrelated to differences in ion trajectories in the particular ion source geometry investigated here.

\section{Metastable-stimulated Desorption Effects}

Cody et al. have suggested that desorption in DART may include both thermal and non-thermal processes, such as bombardment of the sample surface by metastables or ions [4]. According to the results presented thus far, the former can be considered as being a predominant pathway for energy deposition. Examples of the latter include reactive chemical sputtering [35], and metastable-stimulated desorption (MSD). In MSD metastable rare gas atoms are directed at a surface in vacuo and collide with the outermost surface of the sample, creating an electron hole via Auger deexcitation of the metastable species [36, 37]. This process can create a repulsive potential between the surface and analyte stimulating desorption. To investigate the pres- 
(a)
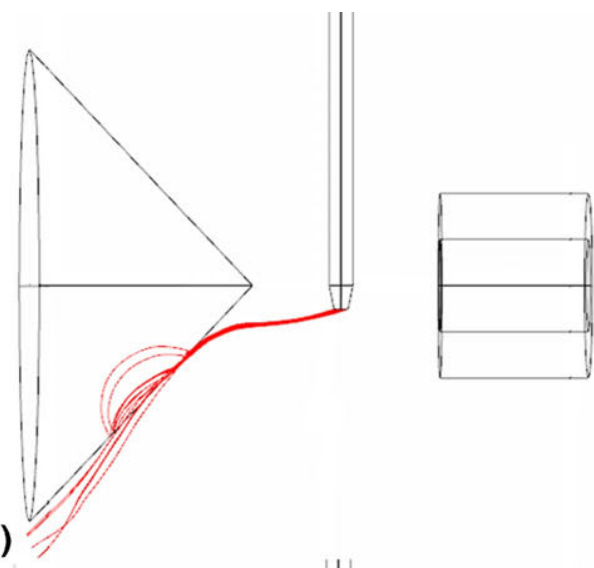

(b)
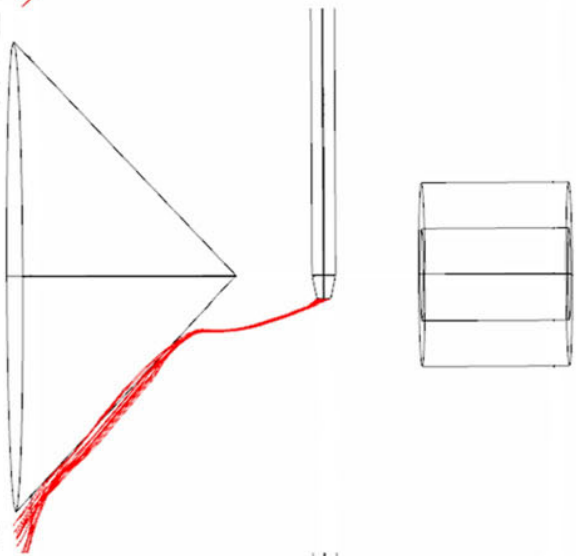

(c)
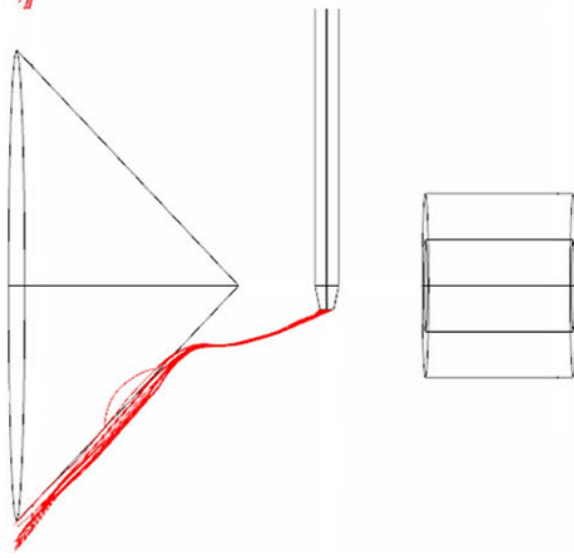

Figure 5. Particle tracing plots showing simulated trajectories of neutral particles originating on the bottom surface of the sample capillary at helium gas flow rates of (a) $2 \mathrm{~L} \mathrm{~min}^{-1}$, (b) $4 \mathrm{~L} \mathrm{~min}^{-1}$, and (c) $6 \mathrm{~L} \mathrm{~min}^{-1}$.

ence of these nonthermal desorption processes, survival yield experiments were attempted using ambient temperature helium metastables. Benzylpyridinium ions were not detected from either slurries, liquid solutions, or from completely dried salts under any of the conditions previously tested, suggesting the absence of $\mathrm{E}_{\text {int }}$ deposition pathways involving nonthermal desorption processes.

\section{Conclusions}

Utilizing the "survival yield" method, the $\mathrm{E}_{\text {int }}$ distributions of a series of $p$-substituted benzylpyridinium ions was compared between ESI and DART-TOF MS. Although differences in some experimental settings were unavoidable to produce high quality data, ESI was the "softer" of the two ionization techniques with some overlap in energy distributions with DART. Thermal ion activation was a major contributor to $\mathrm{E}_{\text {int }}$ deposition in DART. Additionally, in-source CID in the first pumped region of the mass spectrometer contributed to DART $E_{\text {int }}$ deposition as gas flow rates and temperatures increased. Although the work presented here improves our understanding of the fundamental desorption and ionization processes in DART, more work in this area is still necessary. In particular, the effect of ambient humidity, nitrogen gas as a source of metastables, and the contributions of ambient ion transport fluid dynamics to ion activation under other configurations are likely to be worthwhile endeavors for investigation.

\section{Acknowledgments}

The authors thank the U.S. National Science Foundation for the support of this study through a CAREER award to F.M.F. The authors thank Catherine Silvestri for invaluable assistance during synthesis of thermometer compounds.

\section{Appendix A Supplementary Material}

Supplementary material associated with this article may be found in the online version at doi:10.1016/ j.jasms.2010.01.019.

\section{References}

1. Harris, G. A.; Nyadong, L.; Fernández, F. M. Recent Developments in Ambient Ionization Techniques for Analytical Mass Spectrometry. Analyst 2008, 133, 1297-1301.

2. Venter, A.; Nefliu, M.; Cooks, R. G. Ambient Desorption Ionization Mass Spectrometry. Trends Anal. Chem. 2008, 27, 284-290.

3. Van Berkel, G. J.; Pasilis, S. P.; Ovchinnikova, O. Established and Emerging Atmospheric Pressure Surface Sampling/Ionization Techniques for Mass Spectrometry. J. Mass Spectrom. 2008, 43, 1161-1180.

4. Cody, R. B.; Laramee, J. A.; Durst, H. D. Versatile New Ion Source for the Analysis of Materials in Open Air Under Ambient Conditions. Anal. Chem. 2005, 77, 2297-2302.

5. Horning, E. C.; Carroll, D. I.; Dzidic, I.; Haegele, K. D.; Horning, M. G.; Stillwell, R. N. Atmospheric Pressure Ionization (API) Mass Spectrometry. Solvent-Mediated Ionization of Samples Introduced in Solution and in a Liquid Chromatograph Effluent Stream. J. Chromatogr. Sci. 1974, 12, 725-729.

6. Robb, D. B.; Covey, T. R.; Bruins, A. P. Atmospheric Pressure Photoionization: An Ionization Method for Liquid Chromatography-Mass Spectrometry. Anal. Chem. 2000, 72, 3653-3659.

7. Harris, G. A.; Fernández, F. M. Simulations and Experimental Investigation of Atmospheric Transport in an Ambient Metastable-Induced Chemical Ionization Source. Anal. Chem. 2009, 81, 322-329.

8. Kpegba, K.; Spadaro, T.; Cody, R. B.; Nesnas, N.; Olson, J. A. Analysis of Self-Assembled Monolayers on Gold Surfaces Using Direct Analysis in Real Time Mass Spectrometry. Anal. Chem. 2007, 79, 5479-5483.

9. Cody, R. B. Observation of Molecular Ions and Analysis of Nonpolar Compounds with the Direct Analysis in Real Time Ion Source. Anal. Chem. 2009, 81, 1101-1107.

10. Gabelica, V.; De Pauw, E. Internal Energy and Fragmentation of Ions Produced in Electrospray Sources. Mass Spectrom. Rev. 2004, 24, $566-$ 587.

11. Hampton, C. Y.; Silvestri, C. J.; Forbes, T. P.; Varady, M. J.; Meacham, J. M.; Fedorov, A. G.; Degertekin, F. L.; Fernández, F. M. Comparison of the Internal Energy Deposition of Venturi-Assisted Electrospray Ionization and a Venturi-Assisted Array of Micromachined Ultrasonic Electrosprays (AMUSE). J. Am. Soc. Mass Spectrom. 2008, 19, 1320-1329. 
12. Nefliu, M.; Smith, J. N.; Venter, A.; Cooks, R. G. Internal Energy Distributions in Desorption Electrospray Ionization (DESI). J. Am. Soc. Mass Spectrom. 2008, 19, 420-427.

13. Gabelica, V.; Schulz, E.; Karas, M. Internal Energy Build-up in MatrixAssisted Laser Desorption/Ionization. J. Mass Spectrom. 2004, 39, 579-593.

14. Tang, H. W.; Ng, K. M.; Lu, W.; Che, C. M. Ion Desorption Efficiency and Internal Energy Transfer in Carbon-Based Surface-Assisted Laser Desorption/Ionization Mass Spectrometry: Desorption Mechanism(s) and the Design of SALDI Substrates. Anal. Chem. 2009, 81, 4720-4729.

15. Harrison, A. G. Energy-Resolved Mass Spectrometry: A Comparison of Quadrupole Cell and Cone-Voltage Collision-Induced Dissociation. Rapid Commun. Mass Spectrom. 1999, 13, 1663-1670.

16. Burinsky, D. J.; Williams, J. D.; Thornquest A. D. Jr.; Sides, S. L. Mass Spectral Fragmentation Reactions of a Therapeutic 4-Azasteroid and Related Compounds. J. Am. Soc. Mass Spectrom. 2001, 12, 385-398.

17. Katritzky, A. R.; Watson, C. H.; Dega-Szafran, Z.; Eyler, J. R. CollisionallyActivated Dissociation of N-Alkylpyridinium Cations to Pyridine and Alkyl Cations in the Gas Phase. J. Am. Chem. Soc. 1990, 112, 2471-2478.

18. Kenttamaa, H. I.; Cooks, R. G. Internal Energy Distributions Acquired through Collisional Activation at Low and High Energies. Int. J. Mass Spectrom. Ion Processes 1985, 64, 79-83.

19. Vékey, K. Internal Energy Effects in Mass Spectrometry. J. Mass Spectrom. 1996, 31, 445-463.

20. Wysocki, V. H.; Kenttamaa, H. I.; Cooks, R. G. Internal Energy Distributions of Isolated Ions after Activation by Various Methods. Int. J. Mass Spectrom. Ion Processes 1987, 75, 181-208.

21. Vékey, K.; Brenton, A. G.; Beynon, J. H. Electron Capture Induced Decomposition of the Benzene $\mathrm{C}_{6} \mathrm{H}_{6}{ }^{2+}$ Ion. J. Phys. Chem. 1986, 90, 3569-3577.

22. Collette, C.; De Pauw, E. Calibration of the Internal Energy Distribution of Ions Produced by Electrospray. Rapid Commun. Mass Spectrom. 1998, $12,165-170$.

23. Collette, C.; Drahos, L.; De Pauw, E.; Vékey, K. Comparison of the Internal Energy Distributions of Ions Produced by Different Electrospray Sources. Rapid Commun. Mass Spectrom. 1998, 12, 1673-1678.

24. Peng, W. P.; Goodwin, M. P.; Chen, H.; Cooks, R. G.; Wilker, J. Thermal Formation of Mixed-Metal Inorganic Complexes at Atmospheric Pressure. Rapid Commun. Mass Spectrom. 2008, 22, 3540-3548.

25. Gabelica, V.; Pauw, E. D.; Karas, M. Influence of the Capillary Temperature and the Source Pressure on the Internal Energy Distribution of Electrospray Ions. Int. J. Mass Spectrom. 2004, 231, 189-195.
26. Drahos, L.; Heeren, R. M. A.; Collette, C.; De Pauw, E.; Vekey, K. Thermal Energy Distribution Observed in Electrospray Ionization. I. Mass Spectrom. 1999, 34, 1373-1379.

27. Fisenko, S. P.; Wang, W. N.; Lenggoro, I. W.; Okyuama, K. Evaporative Cooling of Micron-Sized Droplets in a Low-Pressure Aerosol Reactor. Chem. Eng. Sci. 2006, 61, 6029-6034.

28. Campbell, V. L.; Guan, Z.; Laude, J.; D. A. Selective Generation of Charge-Dependent/Independent Ion Energy Distributions from a Heated Capillary Electrospray Source. J. Am. Soc. Mass Spectrom. 1994, 5, 221-229.

29. Kebarle, P. A Brief Overview of the Present Status of the Mechanisms Involved in Electrospray Mass Spectrometry. J. Mass Spectrom. 2000, 35 804-817.

30. Kebarle, P.; Peschke, M. On the Mechanisms by Which the Charged Droplets Produced by Electrospray Lead to Gas Phase Ions. Anal. Chim. Acta 2000, 406, 11-35.

31. Laramee, J. A.; Cody, R. B. Chemi-Ionization and Direct Analysis in Real Time (DART) Mass Spectrometry. Vol. VI, Ionization Methods. In Encyclopedia of Mass Spectrometry; Gross, M. L.; Caprioli, R. M., Eds.; Elsevier: Amsterdam, 2007; p. 377-387.

32. Milligan, D. B.; Wilson, P. F.; Freeman, C. G.; Mautner, M. M. N McEwan, M. J. Dissociative Proton Transfer Reaction of $\mathrm{H}_{3}{ }^{+}, \mathrm{N}_{2} \mathrm{H}^{+}$, and $\mathrm{H}_{3} \mathrm{O}^{+}$with Acyclic, Cyclic, and Aromatic Hydrocarbons and Nitrogen Compounds, and Astrochemical Implications. J. Phys. Chem. A 2002, 106, 9745-9755.

33. Nicol, G.; Sunner, J.; Kebarle, P. Kinetics and Thermodynamics of Protonation Reactions $-\mathrm{H}_{3} \mathrm{O}^{+}\left(\mathrm{H}_{2} \mathrm{O}\right)_{h}+\mathrm{B}=\mathrm{BH}^{+}\left(\mathrm{H}_{2} \mathrm{O}\right)_{b}+(h-b+$ 1) $\mathrm{H}_{2} \mathrm{O}$, Where $\mathrm{B}$ is a Nitrogen, Oxygen or Carbon Base. Int. J. Mass Spectrom. Ion Processes 1988, 84, 135-155.

34. Schmidt, A.; Bahr, U.; Karas, M. Influence of Pressure in the First Pumping Stage on Analyte Desolvation and Fragmentation in NanoESI-MS. Anal. Chem. 2001, 73, 6040-6046.

35. Cooks, R. G.; Ast, T.; Mabud, A. Collisions of Polyatomic Ions with Surfaces. Int. J. Mass Spectrom. Ion Processes 1990, 100, 209-265.

36. Kurahashi, M.; Yamauchi, Y. Metastable Helium Atom Stimulated Desorption of $\mathrm{H}^{+}$Ion. Phys. Rev. Lett. 2000, 84, 4725-4728.

37. Kurahashi, M.; Yamauchi, Y. Observation of $\mathrm{H}^{+}$Desorption Stimulated by the Impact of Metastable Helium Atoms. Surf. Sci. 2000, 454/456, $300-304$ 